\title{
English Interpreting Teaching from the Perspective of
}

\section{Interpreter Qualities}

\author{
Jiao $\operatorname{Dan}^{1 *} \&$ Yang Chunyu ${ }^{1}$ \\ ${ }^{1}$ Henan University of Technology, Henan, China \\ *Jiao Dan, Email: 85679689@qq.com
}

Received: October 23, 2017 Accepted: November 7, 2017 Online Published: November 20, 2017

doi:10.22158/selt.v5n4p781 URL: http://dx.doi.org/10.22158/selt.v5n4p781

This article was realized with the support of Henan Provincial Philosophy Scientific Planning Project 2015BYY014; Henan Provincial Key Scientific Research Project in Higher Education 17A880006z; Henan Provincial Educational Scientific Planning Key Project [2016]-JKGHA-0015 and Education Department of Chinese Government Project 16YJC740026.

\begin{abstract}
With the frequent development of the international communication and cooperation, the interpreter's role is much more important than ever before in the modern society. In order to meet this demand, more and more China's universities have set up undergraduate translation major, and (or) set up a professional Master of Translation and Interpretation (MTI). Under this circumstance, the universities become the main force of interpreter training. This paper mainly studies the English interpreting teaching from the perspective of interpreter qualities focusing on eight qualities: language competence, knowledge storage, interpreting quotients (communication skills, thinking consciousness, reflexes and concentration, learning ability, psychological quality, service consciousness). Through the study on the interpreters' qualities, this paper aims at providing the references for interpreting teaching in universities both for interpreting teachers and trainers.
\end{abstract}

\section{Keywords}

English teaching, interpreting teaching, qualifications, interpreters, China's universities

\section{Introduction}

In terms of English teaching, it is usually divided into many modules: listening, speaking, reading, writing, and interpreting. English interpreting teaching, as an important part in English teaching, includes teaching team construction, admission control, skill teaching, conference practice teaching, etc. The core of interpreting teaching is to train qualified interpreters with sound language competence, knowledge storage and interpreting quotients. 
The process of interpreting can be divided into three parts: information input, information storage and information output. And the process of interpreting is the process of information processing and transmission. Whether the information is complete, accurate, timely or smooth is the fundamental element of the interpretation. The interpreting process is that an interpreter takes information from one language symbol, to another one by processing it appropriately. "Information" is the fundamental point of the interpreter, the interpreter always revolves around the information in two or more language symbols, the information comes from the symbol, but also to the symbol. It is a cognitive process, especially of the interpreter. Among which the interpreters repeatedly carry out the process of "thinking construction-thinking transformation-externalization of thinking".

The success or failure of the interpreter depends on whether the interpreter can handle the appropriate information in an appropriate way at an appropriate node. It's an advanced mind and brain cognition using the ear and mouth. High-quality interpretation should have high level of source information, and the expression is with acceptability. The interpretation should be accurate, fast, smooth and beautiful. A professional interpreter should first be a service provider. The primary duty of the interpreter is to provide communication services, and to convey information to all parties participating in the communication. In addition, the interpreter also serves as a bridge between impartial mediation and communication. Interpreting activities are often the complex communication activities those with multi-level, multi-faceted, and multi-angle. The communication objects may include: speakers, listeners, organizers, co-organizers, equipment providers, etc.

In the role of "communication bridge", the interpreter has great initiative, and sometimes may play a certain role as participants and managers. Therefore, the role of interpreters is a three-dimensional, complex, contradictory dynamic system, which requires the interpreter with an excellent quality. This paper is written with a tentative intention to improve the current interpretation teaching situation in China from the perspective of the qualities an interpreter must be equipped with.

\section{The Qualifications of Interpreters}

With the development and increasingly ubiquitous, external exchanges in politics, economy, culture and other areas, the globalization and economic integration pattern have begun to take shape. International communication has permeated all levels of the country's daily life. And today's college students are the mainstay of international communication. To effectively achieve the results of international communication interpretation, the quality of university interpreters must be strengthened. Therefore, the focus on improving the quality of international exchange interpretation of China's universities is becoming more urgent.

The qualifications of interpreters have been discussed for years. Regard to the definition of the quality of the interpreter, the International Conference Interpreter Association has the following requirements for the quality of the Conference Interpreter: with bilingual or multilingual competence; fully prepared with special knowledge. On this basis, Wang (2007) proposed that qualifications of the interpreters can 
be divided into intelligence factor module and non-intelligence factor module. The basic elements of the interpreter's quality are sketched out in a more comprehensive way.

After the summary, the interpreter should have three basic qualifications: language skills, knowledge reserves and interpreters. Which interpreters also include good communication skills, thinking ability, responsiveness, attention, learning ability, psychological quality and service awareness.

\subsection{Language Competence}

Language competence, which means a good mastering of both the source and target language, is a requirement for the quality of interpreting. Interpreters have good language competence to ensure information input and output of high quality. Which means that they should have a good grasp of the source language and the target language, and continuous trying to improve their language level.

The source language is the first one, actually it is the mastery of the mother tongue. Correctly understand the original text, proficient use of native language is a basic condition to ensure the quality of translation. For example, "they have done their best too to ensure that foreigners do not go without", If this is translated as “他们也尽力保证外国人不缺少”, it is an obscure meaning. According to the usage of going without the original context, the correct meaning of this sentence should be “他们还尽量保证外国人 不缺少他们所需要的东西”. Another common saying goes “There's no pot so ugly, it can’t find a lid”, “缽 儿再丑，配个盖子不发愁” is much better than “姑娘无论多么丑也能配个汉子”. Its rhyme is in a humorous and meaningful, it's a wonderful Quotes. This shows that if the interpreter's English or Chinese lack of literacy, translation quality will not be the basic guarantee.

And the target language is the followed one. What are the requisites for determining sufficient competence in a foreign language so as to serve as an interpreter? This is a frequently asked question but it is difficult to answer satisfactorily. Certainly, one must have some feeling for different types of style in a foreign language. Language sometimes can be magical, the plays on words, and especially the subtle double meanings which can be the basis for saying one thing while meaning another. Perhaps master this kind of skills is the most reliable index for adequacy and competence in a foreign language. International communication interpreters in China's universities should (1) Have a strong ability of listening. This ability ranks above all. Mainly including listening of mother language and target languages. The apt ears are essential since they are the main channel for information reception. (2) Master the English language and speak English fluently. Interpreters' speaking skill doesn't refer to the common sense of having a good command of spoken language in foreign language communication. It is a skill for an interpreter as "the ability to use a foreign language to make spontaneous and unscripted contributions and presentations on matters when complex language is required". (3) An acute ear and a glib tongue top the legal table of language abilities. However, interpreting competence isn't gained only with earphones, tapes or in the course of face-to-face communication; it is also perfected with desk, books, dictionaries and pens. The work of an interpreter requires maximum proficiency in the target language as well as in-depth understanding of the source language, along with a thorough grasp of the subject matter treated. 


\subsection{Language Competence}

\subsubsection{Cultural Knowledge}

Interpretation involves language as well as culture. An interpreter should know foreign culture as well as the culture of his own people. Moreover, an interpreter should make continuous comparisons between the two cultures because interpretation equivalence in its very sense should be matched in meanings, functions, scopes and feelings in the two cultures. If language competence merely means being bilingual, it is not enough, because it should also be matched by being bicultural. That is to say, one must have a specific knowledge of the culture in question, or "at-fulsomeness" in both cultures.

A language is a living phenomenon. It does not exist apart from the culture where it is spoken and written. It communicates not only the names of objects and different kinds of action, but also feelings, attitudes, beliefs, and so on. To be fully familiar with a language, one must also be familiar with the culture in which the language is used and indeed, with the people who use it, their ways, manners, beliefs and all that goes into making a culture. One must be able to recognize subtle ironies and literary allusions. A sufficient knowledge of the respective cultures and the subject matter is indispensable.

At the same time, we should pay attention to absorbing and enriching all kinds of basic knowledge, and should have a better understanding of the history, geography, politics, military affairs, diplomacy, economy, culture, science, customs, etc. Only to do this, can we better understand the source text to interpret more accurate, and more perfect.

An example goes:

Speaker: After lunching in the basement of the Medical School, Philip went back to his rooms. It was Saturday afternoon, and the landlady was cleaning the stairs.

Interpreter: 在医学院地下室吃过饭后，菲利普回到自己的寓所，那是一个星期六的下午，女房东正在打扫楼梯.

In the UK, people often rented a room from people who was called landlord or landlady. If someone lack the background knowledge, perhaps mistranslated it as 女地主.

The importance of social-cultural background information that can hardly be overemphasized has been touched upon above. But the question of subject matter information is also becoming increasingly acute in view of the fact that more and more translating involves "language for special purposes", or the technical use of language involving highly specialized subjects. The explosion of information within the last century means that there are no longer any polymaths or people who have an effective knowledge of all domains of learning (Kong, 1999, pp. 82-83).

As an international communication interpreter in China's universities, deep cultural accomplishment is required for successful cultural exchange and cooperation at universities. First of all, the foreign visitors from higher educational universities from all over the world are mostly with high diplomas and other types of qualifications. Most of the foreign visitors hold a strong interest in Chinese culture and they have a strong desire to cooperate with China. So do the interpreters, as the primary point of contact with foreigners, bear heavy responsibilities to transmit the essence of Chinese culture to them. The interpreters not only stand for the image of Chinese universities but also stand for the culture of 
China. Under such requirements, foreign affairs interpreters at universities must study hard about the representative culture of China in preparation for conveying the culture to foreign visitors when the opportunities arise.

\subsubsection{Professional Knowledge}

Of course, it is also necessary to be familiar with some interpretation theories and master some common methods and techniques. Compared with writing translation, oral interpretation has its own unique skills such as interpretation style, interpretation notes, interpretation expression, interpretation obstacles solutions, and interpretation remedies and so on. In short, the language knowledge systems of interpreters, the ability of language expression, the capabilities of response, the ability to combine information and the knowledge of cultural backgrounds are all influential factors on the success or failure of interpretation. Therefore, the interpreters should have a systematic study, intensive training and constant practice to master the interpretation skills.

\subsubsection{Encyclopedia Knowledge}

Different knowledge requirements in interpretation are with respect to knowledge requirements. Interpreters are expected to be equipped with more pre-existing knowledge than translators. Interpreters are usually working under high time pressure and have to resort to their own knowledge repository on the spot. "Who helps himself will be helped by God". There is little possibility to consult encyclopedia or dictionaries. They might stop and ask the speaker or the expert on the premises to explain a certain terminology, which costs time and if frequently done, the interpreter's credibility will be at stake.

Interpreters must familiarize themselves with the interpretation. We may consider that if an interpreter had no idea of grain storage technology, how could he/she do an excellent job in the interpretation of a cooperation negotiation in Chinese and foreign food technology? Furthermore, interpreters must also have a broad command of relevant knowledge. For example, when carrying out a foreign affairs interpretation in the field of scientific technology, we need to know about all the technical regulations, technical standards and requirements, and to do a good job of advanced technology and innovation research through the index of patent literature from the countries all over the word. It is equally important to know about the various intellectual property treaties and so on.

As we know, traditional Chinese medicine is very popular and well-known in the world. As an international affairs interpreter in medical universities, he/she must master the professional proper names in medical circles and use the method of interpretation with explanations to facilitate the mutual understanding. For example, “针炎学” "science of acupuncture and combustion of traditional Chinese medicine"; “中医推拿学” science of tuina of traditional Chinese medicine”; “伤寒” “cold pathogenic disease"; “瘟疫” “epidemic infectious disease”; “疮疾” “malaria”; “哮病” “asthma”; “中风” “apoplexy” etc. Interpreters may add some explanations to these typical traditional Chinese medical terms to foreigners to help them gain a better understanding, first of all, and to master these professional English names. 


\subsection{Interpreter Quotient}

\subsubsection{Communication Skills}

The direct purpose of interpreting is to promote communication, and the interpreter should firstly be good at communicating with people. During the interpreting, the interpreter needs to quickly understand, judge, and make decisions that facilitate communication. The interpreter should be good at communicating with all kinds of people, including customers, speakers, listeners, colleagues, equipment personnel, service personnel and so on. The interpreter should get the initial point of what they see, listen and speak.

\subsubsection{Thinking Consciousness}

Interpretation is a kind of special thinking activity. Learning interpretation is mainly to study a interpreting thinking with information processing as its main task, and the core of interpreting thinking is logical thinking - analysis and inductive thinking. For the interpreters, rich image thinking and instant inspiration thinking are important. In addition, the rich image of thinking and instantaneous inspiration thinking is important. It is not because of the amazing memory, but the logical thinking-based information processing capacity that the interpreter can "never forget". Interpreters should have both divergent thinking (sending) and strong convergence of thinking (receiving). There should be "sparks of inspiration" between sending and receiving. Interpreters need six points of reason, three points of sensibility and one point of spirituality.

\subsubsection{Reflexes and Concentration}

The interpreter needs to capture all kinds of information, such as voice signal, image signal, language form, meaning, emotion, style, etc., which is mainly related to the quality of interpretation, and quickly filter, process, store and output. This process can only be done by an agile interpreter. In addition, some speakers spoke longer, and the interpreters needed a high degree of concentration. Sometimes the half-day alternation was completed by an interpreter, who needed to focus on hours in a row. The heart of interpreter seems to have a "switch", the "switch" will open when plays begin, at this time, the interpreter need be focused, and responsive in a power state or peak experience state. After the end of the "switch" off, the interpreter need to relax, have a rest and further accumulation of knowledge, skills, so as to prepare for the next one.

\subsubsection{Learning Ability}

Learning ability is first reflected in the ability of interpreters to continually absorb new knowledge, new information and knowledge. Interpreting is a profession that needs constant learning. Interpreters are often the people who do not understand the subject matter of communication in the field of communication. But they are given the mission of helping experts in various fields to communicate. Each translation may include a number of ideas, techniques, and knowledge. The Learning ability is also reflected in the interpretation of learning, that is, the plasticity of students, such as timely removal of bad translation habits, quick grasp of interpretation skills, timely adjustment of self-interpretation program, timely absorption of fresh language nutrients. 
In addition, the interpreter should expand his efforts to study the knowledge required for the task. The goal of the study is to become an expert in the process of interpretation, because knowledge is always in development and can not only be submerged in a particular area for a long time.

\subsubsection{Psychological Quality}

Interpreters are often placed under the crowd, to face all the celebrities eloquent wisdom of the speech, the audience eager to seek insight, flashing dazzling light and shadow, flocked to the lens, and the pressure can be imagined. At this point, the interpreter's professional ability should be based on super psychological quality.

Since the interpretation of foreign affairs work concerns international affairs with great responsibilities, heavy tasks and serious consequences, the interpreters need to constantly strengthen their interpretation ability, enhance their self-confidence, train mental and physical skills and improve the ability to confidently respond on-the-spot. There is always the risk that some fresh interpreters with little practical experience will become so stage-frightened that their minds will empty and they will become speechless when attempting on-the-spot interpretation. There are several factors leading to this phenomenon, for example, the interpreters' lack of confidence, lack of the preparation of professional knowledge and interpretation background, the receptors they are facing are of intimidatingly high rank officials or presidents. Therefore, to avoid such scenarios, interpreters have to cultivate the high quality level of mental discipline and practice frequently.

\subsubsection{Service Consciousness}

Interpreting is essentially a kind of skill-based service. The service consciousness is very important for interpreters. Interpreters often go to important occasions and contact expert celebrities. Therefore, it is necessary to locate the service role, maintain peace and mind, and do not be overwhelmed, and can not be busy with the signature and no time to work.

Interpreting is a time-consuming task which also involves great energy. As Jin and Nida say, an interpreter must be involved in the task both with his or her mind and spirit. The devotion to one's task will be ultimately decisive in the making of a good interpreter, as can be found in such striking evidence in the life of every past master of this difficult art (1984, p. 30).

In interpreting teaching, these eight qualifications of interpreter should be totally considered during the teaching process.

\section{Understanding from the Perspective of Newmark's Translation Theory}

At present, China's international communication interpreters have realized the importance of the interpreting method and have done research on this topic, but most of them contribute papers on how to qualitatively improve the interpretation of China's IC from their own experience, instead of from the perspective of translation theories. Nida states in his forward to Peter Newmark's Approaches to Translation, "Professor Newmark's major contribution is in a detailed treatment of semantic vs. communicative translating", which settles the conflict of loyalties, the gap between emphasis on source 
and target language which always remain as the overriding problems in translation theory and practice. With the knowledge that Newmark's semantic and communicative translating approach is applicable to "a wide range of discourse and related problems" (Newmark, 2001), I carefully read through his work Approaches to Translation, which encourages me to take it as the theory to guide the interpretation of international communication in China's universities.

After formulating the characteristics and background of international affairs interpretation in China's universities, in accordance with the features of international affairs in China's universities and analysis of the translating theories, this paper emphasizes the effects of the explanatory interpretation method and states the applications of this method practically in the international affairs of China's universities. As far as the current China's international cooperation and exchanges situation is concerned, competent interpreters are sure to play important roles in the development of China's international affairs. The level of higher education in a country is an important representative of its comprehensive national strength. Since native English people may not fully understand the original, they may give their own understanding of the original, which may be full of misunderstandings and corresponding misinterpretations, which goes against the main purpose of China's IC (Pan, 42). The reason why Graham insisted that translation of Chinese work into English could only be done by interpreters who are native speakers of English rather than Chinese is that Chinese interpreters always give awkward interpretations, which sound more like Chinese works than anything else, and which disrupts English syntax without letting the readers know the syntax of the Chinese (Graham, 1965, p. 24). It is indeed the most difficult for a Chinese IC C-E (Chinese to English) interpreter to think of the message in terms of the receptor language frame of reference based on the presuppositions and values of culture.

It is agreed that the main aim of the IC C-E materials interpreter is to produce as nearly as possible the same effect on his readers as the speaker expects, so from what I have stated, the interpreter actually has a high flexibility to deal with interpretation problems with the interpreting techniques especially with the method of explanatory interpretation but meanwhile IC interpreting is much more demanding. First of all, the interpreter should have a good command of both his own language and the target language, which helps the interpreter understand the original and produce effective interpretations. However, just being bilingual is not enough in interpreting.

Second, the interpreter of international communications in China's universities should spare no efforts to learn from China's international affairs policy and keep up with the times, study translating theories and properly apply the theories in the practical interpretation setting, so that his interpretation will be more idiomatic and be warmly welcomed by his target receptors. Many people may be fully competent in two or three languages, but produce incredibly inadequate interpretations.

Third, the interpreter should have a good understanding of his target receptors, and know clearly which clichés, terms and even sentences which do no help to the target readers' correct understanding of China can be got rid of, know what desired stimulus should be produced, and know how to modify and reorganize the original to help the author obtain the optimum reaction from the reader, know the 
identification of foreigners and the background of the foreigner's education and politics as well as his countries'.

Fourthly, the interpreter should have the ability to tell the subtle distinctions between the synonyms in the target language. In interpreting, the interpreter may often come across the situations where the target language has a number of synonyms to express the sense of a source language word and he should be very cautious and choose the word he considers stylistically most fitting more than the word that most obviously translates the source language word.

\section{Conclusion}

In today's world, international exchanges in politics, economy, science, culture and trade become more and more frequent. In this context, owing to the language barrier, interpreter shoulders the responsibility to facilitate the exchange more smoothly and effectively. However, shortage of the qualified interpreter becomes all the more acute. Correspondingly, to cultivate the qualified interpreter as soon as possible becomes an important task at present. This is in line with the ultimate goal of the interpreting teaching, students need to be equipped with significant qualities of competent interpreter so as to they can successfully interpret in the real-life situation. Therefore, it is a must for experts and interpreting teachers to quicken the step of theoretical research and practical application in order to improve the interpreting teaching.

In short, the successful interpreting teaching is related to the development of universities and even the higher education of China in the world competition. Therefore, language researchers and the practical interpreters in international communication have reached a final agreed conclusion that the qualifications of international communication interpreters will definitely promote the quality of foreign affairs in China's universities. Besides, from the perspective of interpreter competence, the teaching contents should be flexible changed.

Lastly, what I would like to reiterate is that, as R. Jacobson states, one kind of language as a symbol could not be replaced by another kind of language without losing any associate meaning, but information given in one kind of language is of course no problem to be conveyed in another language in interlingual communication. Therefore, the translator should always keep in mind that in IC C-E translation practice loss of meaning in IC C-E translation is inevitable, since it focuses on conveying the maximum message and receiving almost identical reader-response as the author expects.

With today's tendency towards globalization, China's IC makes a lot of sense in projecting China's international images, so effective C-E translations of IC is an acutely felt need. However, there still exist many problems in the quality, intelligibility, and acceptability of such translations. That is why the author chooses C-E translation of IC in China's universities as the research topic of this thesis.

Actually, a lot of previous research on C-E translation of IC has been made in China, but most of it has been empirical. On the basis of the achievements made so far by previous researchers, the author has tried to establish a new model and approach to this topic by means of Newmark's communicative 
translation theory.

The core of successful interpreting teaching is to select students with sound language competence, rich knowledge storage and excellent interpreting quotient, and through the skill training mode of cultivating the student with actual translation thinking (the thought of bilingual information processing), and communicative competence in translation (the ability to convey information by means of bilingualism). The interpreting teaching as an important way to cultivate excellent interpreters, the method will constantly keep pace with the times. With all the foreign affairs practitioners and interpreters' concern and efforts, China's universities' international communication is sure to be more and more effective and thus to propel China's flourishing in the world.

\section{References}

Dai, W. D. (1998). A Concise Course on Linguistics for Students of English (pp. 56-57). Shanghai: Shanghai Foreign Language Education Press.

Duan, L. C. (1988). How to Help Foreigners Know China: Principle and Skills of Communication. Beijing: China Reconstructs Press.

Eric, C. (1991). The Poetics of Imperialism: Translation and Colonization from the Tempest to Tarzan. New York: Oxford University Press.

Ernst, G. (2004). Translation and Relevance. Shanghai: Shanghai Foreign Language Education Press.

Gile, D. (1995). Basic Concepts and Models for Interpreter and Translator Training. Amsterdam and Philadelphia: John Benjamins. https://doi.org/10.1075/btl.8(1st)

Jin, D., \& Eugene, A. N. (1984). On translation. Beijing: Translation and Publishing Corporation.

Kiraly, D. (2000). A Social Constructivist Approach to Translator Education: Empowerment from Theory to Practice. Manchester: St. Jerome Publishing.

Larson, M. L. (1984). A Guide to Cross-Language Equivalence. New York: University Press of America.

Liu, B. Q. (2006). Theoretical Study of Translation and Interpreting. Beijing: China Translation Corporation.

Lu, X. C. (2009). Listening for English Chinese Interpreting: Cognitive Mental Models, Skills and Teaching. Shandong: Shandong Foreign Language Teaching Journal.

Lu, X. C. (2012). A Course on Interpreting Skills-Listening. Beijing: Beijing Language And Culture University Press.

Lu, X. C. (2015). A Course on Interpreting Skills—Consecutive Interpreting. Beijing: Beijing Language And Culture University Press.

Mei, D. M. (2011). An Advanced Course of Interpretation. Shanghai: Shanghai Foreign Language Education Press.

Milton, J., \& Paul, B. (Eds.). (2009). Agents of Translation. Amsterdam and Philadelphia: John Benjamins. https://doi.org/10.1075/btl.81 
Munday, J. (2014). Introducing Translation Studies: Theories and Applications (3rd ed.). Beijing: Foreign Language Teaching And Research Press.

Newmark, P. (2001). Approaches to Translation. Shanghai: Shanghai Foreign Language Education Press.

Nida, E. A. (2001). Language and Culture. Shanghai: Shanghai Foreign Language Education Press.

Nida, E. A., \& Charles, T. (1969). The Theory and Practice of Translation. Leiden: Brill.

Pinkham, J. (2000). The Translator's Guide to English. Beijing: Foreign Language Teaching And Research Press.

Robinson, D. (1997). Translation and Empire: Postcolonial Theories Explained. Manchester: St.Jerome.

Su, H. D. (2017). Research on Training Strategy of Practical Undergraduate Interpreters in Local Universities. Hei Longjiang: Journal of Higher Education, 2, 167-168.

Tejaswini, N. (1992). Siting Translation: History, Post-Structuralism, and the Colonial Context. Berkeley and Los Angeles: University of California Press.

Zhang C. P, \& Chen, W. (2017). An Investigation on the Training of Conference Interpreting Talents in Guangxi Universities. Guangxi: Journal of Guangxi Radio and TV University, 2, 82-91. 